\title{
Characteristics and Electrochemical Performances of Nitrogen- doped Graphene Prepared using different carbon and nitrogen sources as Anode for Lithium Ion Batteries
}

Hong Liu, Yichen Deng, Jinxiang Mao, Minmin Chen, Jinxia Hu, Zhicheng Ju, Zheng Xing and Xichuan Cao*

Department of Energy Materials and Devices, School of Materials and Physics, China University of Mining and Technology, Xu Zhou 221000, China

*E-mail: xichuancao@cumt.edu.cn

doi: $10.20964 / 2021.04 .03$

Received: 4 November 2020 / Accepted: 24 January 2021 / Published: 28 February 2021

Nitrogen-doped graphene (NG) materials were successfully synthesized in one step by the restricted template method. Specifically, the use of different nitrogen sources and carbon sources makes the content of various nitrogen doping structures in NGs different and yields a higher nitrogen doping amount. In the lithium insertion process, nitrogen doping provides more active sites, which effectively improve the specific capacity. As anodes for lithium-ion batteries (LIBs), NGs exhibit excellent electrochemical performance with high reversible specific capacity, good cycle stability, and excellent rate performance.

Keywords: Nitrogen-doped Graphene, Anode material, Lithium-ion batteries

\section{$\underline{\text { FULL TEXT }}$}

(C) 2021 The Authors. Published by ESG (www.electrochemsci.org). This article is an open access article distributed under the terms and conditions of the Creative Commons Attribution license (http://creativecommons.org/licenses/by/4.0/). 